ఠ

\title{
Single-living is associated with increased risk of long-term mortality among employed patients with acute myocardial infarction
}

This article was published in the following Dove Press journal:

Clinical Epidemiology

15 May 2010

Number of times this article has been viewed

\author{
Finn Erland Nielsen \\ Shan Mard \\ Department of Cardiology S, Herlev \\ University Hospital, Denmark
}

Objective: There is conflicting evidence about the impact of social support on adverse outcome after acute myocardial infarction (MI). We examined the relation between single-living and long-term all-cause mortality after MI.

Design: A prospective cohort study of 242 employed patients with MI followed up to 16 years after MI.

Results: A total of 106 (43.8\%) patients died during the follow-up. Single-living nearly doubled the risk of death; after adjusting for potential confounding factors, single-living was an independent predictor of death, with a hazard ratio of 2.55 (95\% confidence interval: $1.52-4.30$ ). Other predictors of death were diabetes mellitus, atrial fibrillation, age, and ejection fraction less than $35 \%$.

Conclusion: Single-living is a prognostic determinant of long-term all-cause mortality after MI.

Keywords: acute myocardial infarction, social support, single-living, prognosis.

\section{Introduction}

Psychosocial factors such as low social support may influence development of heart diseases. ${ }^{1,2}$ The size of an individual's social network is inversely related to mortality, independent of risk factors for heart disease, and unmarried and particularly nevermarried adults are more likely than married adults to die prematurely. ${ }^{3,4}$

Single-living is an easy-to-measure proxy for social isolation and low level of social support. ${ }^{5}$ The association between single-living and higher risk for coronary heart disease has been described in previous research. ${ }^{2}$ There is conflicting evidence about the role of single-living on prognosis after myocardial infarction. Some studies have shown an association between single-living and mortality after myocardial infarction (MI), while other studies have raised questions about such results. ${ }^{5-8}$ Methodological differences, such as variability of follow-up duration and numbers of confounders examined, are potentially plausible explanations for the inconsistency of results. Further research to examine the relationship between single-living and prognosis after MI is, therefore, warranted.

There is no consensus on the definition of social isolation and living arrangements can only partially characterize it. Other factors to consider include connection to the job market and daily contact with colleagues at the work place. Actively employed persons are less likely to experience social isolation. ${ }^{9}$ We hypothesized that among MI patients, being professionally active creates favorable social networks, counteracting the negative
Finn E Nielsen

Dept of Cardiology, Herlev University

Herlev, Denmark

Tel +45 44883748

Fax +45 44884399

Email fierni0I@heh.regionh.dk 
effects of single-living. We examined the prognostic impact of single-living on all-cause long-term mortality among employed patients with a history of acute MI. Furthermore, we examined whether any potential association between single-living and mortality could be explained by other patient characteristics.

\section{Material and methods}

The methods of cohort recruitment, patient characterization and follow-up procedures have been described in detail elsewhere. ${ }^{10}$ Briefly, all surviving, employed MI patients admitted consecutively to the Department of Cardiology, Herlev University Hospital, from October 10, 1990 to March 31, 1993 or to the Department of Cardiology, Gentofte University Hospital, from September 1, 1991 to March 31, 1993 were invited to participate in a study of job prognosis after MI.

Pre-admission data on sociodemographic and medical characteristics were obtained through interviews and clinical examinations in relation to discharge and both an echocardiographic examination and an exercise test were performed. The patients did not participate in any formal rehabilitation program. As a part of the job prognosis study, all patients had a follow-up visit at 6 months and 4 years. Data on longterm survival rates were obtained from the Danish Civil Registration System December 2008. The study was registered and approved by the local hospital ethics committee and by the Danish Data Protection Agency.

\section{Study population}

During the study period, 1214 patients were admitted with MI, $400(32.9 \%)$ of them women. The median age was 69 years (interquartile range 61-75; range 33-96). Of the admitted patients, 324 (26.7\%) were employed and eligible for the study. The diagnosis of MI was confirmed if at least two of the following three criteria were met: presence of symptoms; abnormal electrocardiographic findings; or elevated cardiac enzymes. Of the eligible patients, 82 (25.3\%) were excluded for these reasons: 27 died during the first 6 weeks; 10 lived outside the study area; 2 refused to participate; 7 were not included due to administrative mistakes; 8 were about to retire; 5 were dismissed immediately before the MI; 2 were lost to follow-up after six months; 2 did not fulfill the MI criteria; 1 had a language barrier; 11 had missing data; and 7 patients were excluded for other reasons. Of the 242 patients remaining in the study, $212(87.6 \%)$ were men with a median age of 56 years (interquartile range 49-60; range 33-77), and 30 were women, with a median age of 56 years (interquartile range 49-59; range 36-68).

\section{Socioeconomic status \\ and demographic data}

Self-reported length of school education was registered as a three-level categorical variable ranging from less than 7 years, 8-10 year, and more than 10 years. Job education was assessed on an eight-level categorical scale, subsequently dichotomized for the analysis as 'unskilled' and 'skilled' with all patients having no special skill or training grouped as being unskilled. Self-reported personal annual income was registered on a three-level scale: low ( $<20,000$ Euro), medium (20,000-33,000 Euro) and high income ( $>33,000$ Euro).

\section{Psychosocial factors and spare-time activity}

All patients were asked to report whether they were living alone and whether they were married, never married, divorced, separated, or widowed before the current admission. Due to low numbers of patients in each category, patients living alone were compared with those living with a partner.

Social support was evaluated in a questionnaire. Patients reported frequency of meeting their family members, friends, or other associates and colleagues during their spare-time as 'daily', 'few times per week', 'few times per month', 'seldom', or 'never'. Patients reporting the frequency as 'seldom' or 'never' were grouped as having a 'low' contact level. Further, patients were asked to report the source of social support they could expect during an illness as 'none', 'partners', 'neighbors', 'colleagues' and 'friends'. Patients responding 'none' were defined as having 'low expected support'. All patients were asked to report frequency of attending activities in clubs or organizations during spare-time as 'daily', 'few times per week', 'few times per month'; 'seldom', or 'never'. Patients in the 'seldom' or 'never' categories were grouped in a 'low activities' category. All patients were asked to report sleeping disorders (yes/no), signs of nervous disorders (yes/ no), and frequency of being happy and satisfied with their lives (most of the time, occasionally, seldom/never). Physical activity in spare-time was registered on a four-level scale ranging from sedentary daily activity (low) to heavy physical activity several times per week (high).

\section{Pre-admission medical risk-factor profile}

Patients were asked to assess their physical health status prior to admission on a five-level scale (very good, good, acceptable, bad, very bad). We obtained data on smoking status (current, former, never), diabetes, hypertension, and 
chronic pulmonary disease. Diabetes mellitus was considered present if the patient was on anti-diabetic therapy with diet or medication. Hypertension was defined as a history of hypertension diagnosed by a general practitioner (GP). Chronic pulmonary disease was considered present if diagnosed by the patient's doctor and if patients received medication as treatment for it. Information about previous cardiovascular disease (ie, previous MI, angina pectoris, percutaneous coronary intervention (PCI), coronary artery bypass grafting (CABG), heart failure, and/or stroke) was based on information from the patients and their GPs. Patients were also asked in the interview to report any medical treatment before admission.

\section{Clinical course}

Left ventricular systolic function was estimated by echocardiographic examination during hospital stay and assessed by estimating the wall motion index (WMI). ${ }^{11}$ The WMI was transformed to left ventricular ejection fraction (EF) by multiplying the WMI by $0.3 .^{12}$ The patients were grouped as having severely reduced left ventricular function $(\mathrm{EF}<35 \%)$, moderately reduced $(\mathrm{EF}=35 \%-45 \%)$, or normal function $(\mathrm{EF}>45 \%)$.

Nineteen $(7.7 \%)$ patients did not have an echocardiographic examination. Since these patients had a shorter duration of hospital stay (6 days vs 7 days), fewer of them (risk ratio $[\mathrm{RR}]=0.4 ; 95 \%$ confidence interval $[\mathrm{CI}]$ : 0.10-1.43) showed clinical signs of heart failure during the stay in hospital, and none had clinical signs of heart failure at the 6-month follow-up, it was hypothesized that patients without echocardiographic data probably did not belong in the group with reduced EF, and they were therefore included in the group of patients with EF $>45 \%$ in the analyses. All analyses were repeated after exclusion of patients without echocardiographic examinations.

We examined $200(83 \%)$ patients by exercise test, either on a bicycle $(82 \%)$ or on a treadmill $(18 \%)$. The proportion of patients not undergoing an exercise test was highest among the oldest who were also more likely to suffer from chronic pulmonary disease. Most of the patients (79\%) performed the test after discharge, with the median post-admission time of 22 days (interquartile range 10-30; range 4-60).

Development of heart failure during admission was determined based either on objective signs (eg, reduced left ventricular function [EF less than 45\%]) on echocardiographic examinations, or on clinical or radiological signs of decompensated heart disease. Occurrence of arrhythmias was registered if documented on electrocardiographic examinations either as a self-limiting or a persistent arrhythmia, in spite of treatment needs.

Information about death and date of death was obtained from the Danish Civil Registration System.

\section{Statistical analysis}

All patients were followed from the date of admission until death or end of follow-up, whichever came first. Continuous data were summarized as median, interquartile range (IQR), and range. Categorical variables were reported as frequencies and percentages. Differences in baseline variables were estimated by use of absolute differences and 95\% confidence intervals (categorical variables) or the Wilcoxon rank-sum test (continuous variables).

Survival was estimated by the Kaplan-Meier method. The non-parametric log-rank procedure was used to compare survival times in groups. The proportional-hazards assumption was evaluated graphically with plots of logarithm of negative $\log$ arithm of survival $[\log (-\log \mathrm{S}(\mathrm{t}))]$. The relation between the hazard function and the covariates was modeled by Cox's proportional-hazard regression. Selection of the variables in the models was based on an a priori decision as to which variables were important in combination with the results of the crude associations. The different models were compared by examining the change produced in the value of $-2 \log \mathrm{L}$ by adding or deleting terms; the smaller the value of $-2 \log \mathrm{L}$, the better the model. Schoenfeld- and Cox-Snell residuals were used to check the assumptions and the overall model fit. ${ }^{13}$ Data were analyzed using Stata 11.0 statistical software (StataCorp, College Station, TX, USA).

\section{Results}

\section{Baseline characteristics}

Differences in the prevalence of selected variables of interest, according to the type of living arrangements (single-living vs living with a partner), are given in Tables 1 and 2 . The 30 single-living patients were shown to be younger $(P=0.017)$ and more often unskilled (difference 21.5\%; 95\% CI: 4.6-38.3) (Table 1). Single-living patients had significantly fewer contacts with family members, friends, colleagues and others (difference 19.1\%; 95\% CI: 4.7-33.4) and more frequently reported not expecting support from others during an illness period (difference 22.4\%; 95\% CI: 7.2-37.6\%) (Table 1). Single-living patients were more likely than nonsingle-living patients to receive painkillers (difference, 15.3\%; 95\% CI: 0.7-29.9) before admission and tended to have more frequent block episodes during hospital-stay (difference 10.5\%; 95\% CI: 1.9-22.9) (Table 2). 
Table I Baseline social characteristics of actively employed patients with myocardial infarction, according to living arrangements

\begin{tabular}{|c|c|c|}
\hline Variable & $\begin{array}{l}\text { Living alone } \\
(n=30)\end{array}$ & $\begin{array}{l}\text { Living with } \\
\text { partner }(n=2 \mid 2)\end{array}$ \\
\hline Age (years) & $53(47-57 ; 33-70)$ & $56(51-60 ; 33-78)$ \\
\hline Male (\%) & 80.0 & 88.7 \\
\hline \multicolumn{3}{|l|}{ School-education } \\
\hline$\leq 7$ years $(\%)$ & 33.3 & 37.7 \\
\hline $8-10$ years $(\%)$ & 43.3 & 49.1 \\
\hline$>10$ years $(\%)$ & 23.4 & 13.2 \\
\hline \multicolumn{3}{|l|}{ Job-education } \\
\hline Unskilled (\%) & 30.0 & 8.5 \\
\hline \multicolumn{3}{|l|}{ Personal income ${ }^{a}$} \\
\hline Low (\%) & 3.3 & 8.5 \\
\hline Medium (\%) & 66.7 & 40.6 \\
\hline High (\%) & 26.7 & 49.1 \\
\hline \multicolumn{3}{|c|}{ Self-evaluated health } \\
\hline Very bad/bad (\%) & 10.0 & 8.5 \\
\hline \multicolumn{3}{|c|}{ Happy and satisfied with life } \\
\hline Seldom/never (\%) & 13.3 & 13.7 \\
\hline \multicolumn{3}{|c|}{$\begin{array}{l}\text { Contact frequency with } \\
\text { family/friends/colleagues/ } \\
\text { other }\end{array}$} \\
\hline Low (\%) & 20.0 & 0.9 \\
\hline \multicolumn{3}{|c|}{$\begin{array}{l}\text { Attending activities in } \\
\text { clubs or organizations } \\
\text { during spare-time }\end{array}$} \\
\hline Low activities (\%) & 70.0 & 79.7 \\
\hline \multicolumn{3}{|c|}{$\begin{array}{l}\text { Expected support during } \\
\text { an illness period }\end{array}$} \\
\hline $\begin{array}{l}\text { Low expected } \\
\text { support (\%) }\end{array}$ & 23.3 & 0.9 \\
\hline \multicolumn{3}{|l|}{$\begin{array}{l}\text { Physical activity in } \\
\text { spare-time }\end{array}$} \\
\hline Low (\%) & 76.7 & 87.3 \\
\hline \multicolumn{3}{|l|}{ Alcohol beverages } \\
\hline$\geq 4 /$ day (\%) & 16.7 & 10.4 \\
\hline $\mathrm{I}-3 /$ day $(\%)$ & 16.7 & 35.9 \\
\hline Less/never (\%) & 66.6 & 53.7 \\
\hline Smoking (\%) & 63.3 & 62.7 \\
\hline
\end{tabular}

Note: aive patients did not give information about income.

\section{Long-term mortality}

The median follow-up time was 16.06 years (IQR 9.84-16.80; range, 0.13-18.27). One hundred and six (43.8\%) patients died during the follow-up period.

\section{Unadjusted analyses}

Patients living alone had a significantly lower survival than patients living with a partner (Figure 1). The survival curves began to separate four years after the MI. The crude mortality ratio was 1.82 (95\% CI: $1.10-2.98)$ for single-living patients compared with patients living with a partner. Older age and
Table 2 Baseline clinical characteristics of actively employed patients with myocardial infarction, according to living arrangements

\begin{tabular}{|c|c|c|}
\hline Variable & $\begin{array}{l}\text { Living alone } \\
(n=30)\end{array}$ & $\begin{array}{l}\text { Living with } \\
\text { partner }(n=2 \mid 2)\end{array}$ \\
\hline Prior MI (\%) & 13.3 & 16.5 \\
\hline Diabetes (\%) & 3.3 & 6.6 \\
\hline Hypertension (\%) & 26.7 & 25.0 \\
\hline COPD (\%) & 6.7 & 4.3 \\
\hline \multicolumn{3}{|l|}{ Medication } \\
\hline Painkillers (\%) & 20.0 & 4.7 \\
\hline Nervous disease (\%) & 0 & 3.8 \\
\hline Sleeping disorders (\%) & 20.0 & 15.1 \\
\hline $\begin{array}{l}\text { Length of hospital- } \\
\text { stay (days) }\end{array}$ & $9(8-10 ; 6-22)$ & $8(7-10 ; 3-30)$ \\
\hline EF (\%) & $50.5(4 I-60 ; 24-60)$ & $50(40-55 ; 24-60)$ \\
\hline$<35$ (\%) & 16.7 & 11.8 \\
\hline 35-45 (\%) & 26.7 & 23.1 \\
\hline$>45(\%)$ & 56.6 & 65.1 \\
\hline Heart failure (\%) & 30.0 & 25.5 \\
\hline Atrial fibrillation (\%) & 10.0 & 9.9 \\
\hline VT/VF (\%) & 10.0 & 10.4 \\
\hline Block (\%) & 13.3 & 2.8 \\
\hline Reinfarction (\%) & 0 & 4.7 \\
\hline Thrombolysis (\%) & 50.0 & 59.9 \\
\hline Beta-blocker (\%) & 30.0 & 34.4 \\
\hline ACE-inhibitor (\%) & 20.0 & 22.6 \\
\hline $\begin{array}{l}\text { No exercise-test } \\
\text { performed (\%) }\end{array}$ & 10.0 & 18.4 \\
\hline CABG (\%)* & 30.0 & 23.1 \\
\hline $\mathrm{PCl}(\%)^{*}$ & 13.3 & 9.0 \\
\hline Weight (kg) & 81 (70-87; 52-99) & $80(72-88 ; 47-113)$ \\
\hline
\end{tabular}

Note: aProcedures performed during the first four years after discharge.

Abbreviations: ACE, angiotensin-converting enzyme; Ml, myocardial infarction; COPD, chronic obstructive pulmonary disease; EF, ejection fraction; VT/VF, ventricular tachycardia/ventricular fibrillation; $C A B G$, coronary artery bypass grafting; $\mathrm{PCl}$, percutaneous coronary intervention.

self-reported bad health were associated with greater risk of death in the unadjusted analyses (Table 3). History of diabetes, hypertension, pulmonary diseases, treatment with painkillers, low ejection fraction, clinical signs of heart failure, treatment with angiotensin-converting enzyme (ACE)-inhibitors reflecting low-EF patients, and the lack of exercise-test were all associated with a greater mortality in the unadjusted analyses (Table 4).

\section{Final model}

A model that included variables for single-living, age, diabetes, atrial fibrillation, and low ejection fraction (Table 5) was found to be the best, since other baseline variables or those measured at admission did not improve model fit. 


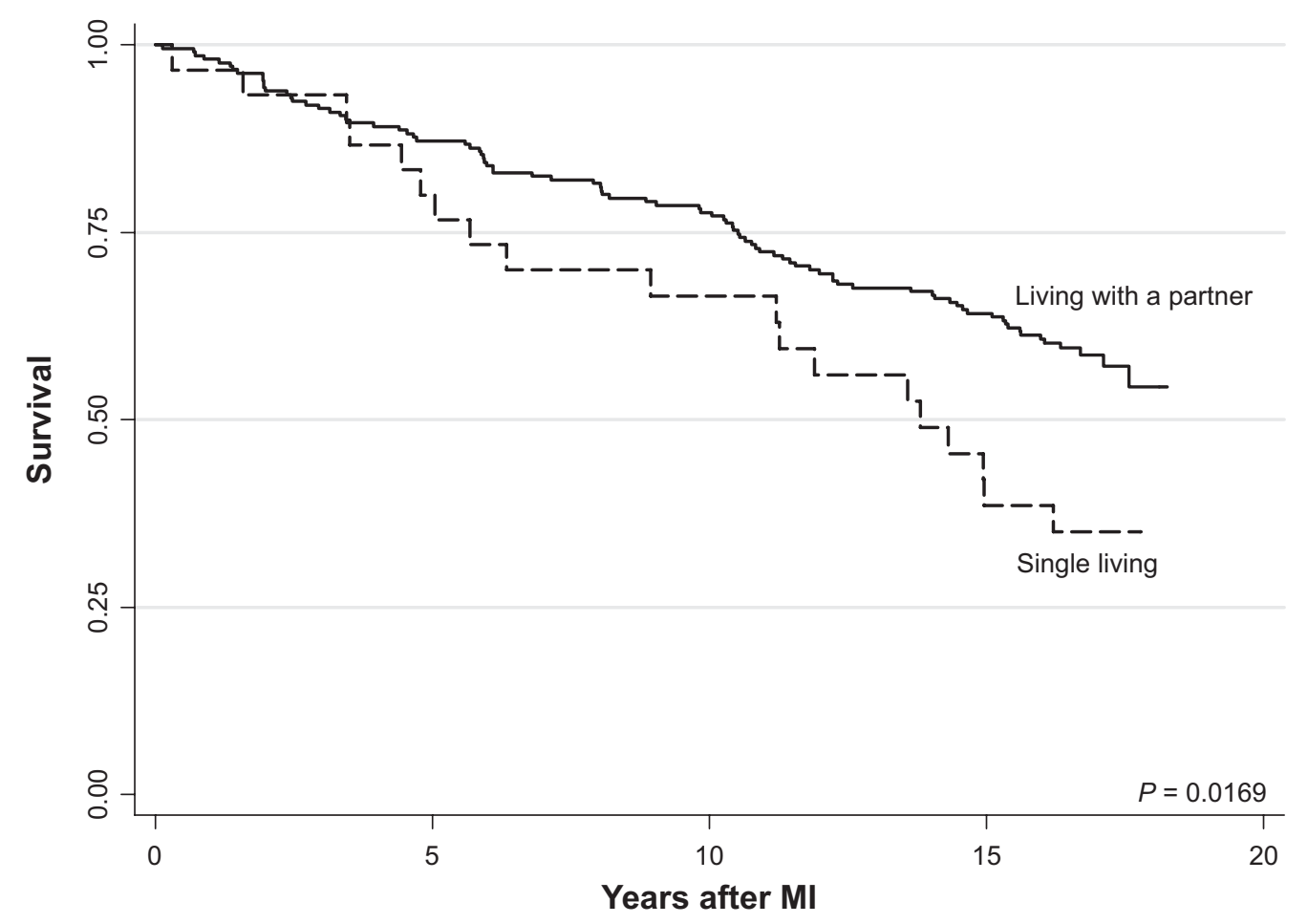

Figure I Kaplan-Meier plot of survival after myocardial infarction in relation to living arrangements. Abbreviation: Ml, myocardial infarction.

Likewise, the interaction terms of the single-living variable with heart failure, atrial fibrillation, or reduced left ventricular function did not improve model fit. Exclusion of patients who did not return to work after discharge or patients without echocardiographic examination did not materially affect the findings.

\section{Discussion}

We found that single-living, used as a proxy for social isolation and reduced social support, is associated with long-term all-cause mortality among actively employed patients with MI. The association between single-living and mortality was independent of the patient's other social and biological characteristics. The findings do not support our initial hypothesis that an employed patient's network from the workplace counteracts the potential negative effects of single-living. Our small sample size precluded a detailed examination of impact on prognosis of single-living according to marital status (never married, divorced, separated, and widowed).

Evidence regarding single-living in relation to outcome after MI is contradictory. Living alone has been identified as an independent predictor of recurrent infarction or death up to four years (mean 2.1 years) after MI, and single-living has been associated with increased long-term mortality for men following MI.,14 Data from the GUSTI-III study failed to show an independent association of any measure of social support, including single-living, with 30-day and one-year mortality after MI. ${ }^{8}$ Similarly, a Canadian study of 3407 patients found no association between single-living and two-year mortality. ${ }^{7}$ In our study, the survival of single-living patients and patients living with a partner began to differ after fours years; variation in the duration of the follow-up period may partially explain these different findings.

Studies with more detailed self-reported measures of social support have likewise reached heterogeneous conclusions. In one study of the influence of social support during the first year after MI, different measures of perceived social support and single-living were unrelated to mortality. ${ }^{15}$ In another study, lower social support was an independent predictor of recurrent events up to nine months after MI. ${ }^{16}$ A high level of social support has been associated with improved outcome among depressed patients, ${ }^{15}$ however, data from another study indicate that higher levels of perceived support are associated with better health outcomes for MI patients without depression. ${ }^{17}$

To confound matters, there is no agreement of a precise definition of social support, while level of social support may vary during a lifetime. ${ }^{3,17}$ Several measures have been suggested and three categories are commonly described: 1) 'social networks' which refers to everyday contacts, 
Table 3 Unadjusted predictors of long-term all-cause mortality among employed patients after acute myocardial infarction

\begin{tabular}{|c|c|}
\hline Variable & Hazard ratio $(95 \% \mathrm{Cl})$ \\
\hline$\overline{\text { Age }}$ & $1.06(1.03-1.09)$ \\
\hline Male sex & $0.80(0.44-1.47)$ \\
\hline \multicolumn{2}{|l|}{ School education } \\
\hline$\leq 7$ years & $0.95(0.53-1.70)$ \\
\hline $8-10$ years & $0.95(0.54-1.67)$ \\
\hline$>10$ years & Ref \\
\hline \multicolumn{2}{|l|}{ Job-education } \\
\hline Unskilled & $1.14(0.64-2.03)$ \\
\hline \multicolumn{2}{|l|}{ Personal income } \\
\hline Low & $1.42(0.72-2.79)$ \\
\hline Medium & $1.03(0.69-1.53)$ \\
\hline High & Ref \\
\hline \multicolumn{2}{|c|}{ Self-evaluated health before admission } \\
\hline Very bad/bad & $1.69(0.95-3.02)$ \\
\hline \multicolumn{2}{|c|}{ Happy and satisfied with life } \\
\hline Seldom/never & $1.12(0.66-1.91)$ \\
\hline \multicolumn{2}{|c|}{$\begin{array}{l}\text { Contact frequency with family/friends/ } \\
\text { colleagues/other }\end{array}$} \\
\hline Low & $1.08(0.40-2.94)$ \\
\hline \multicolumn{2}{|c|}{$\begin{array}{l}\text { Attending activities in clubs or } \\
\text { organizations during spare-time }\end{array}$} \\
\hline Low activities & $0.97(0.6 \mathrm{I}-1.53)$ \\
\hline \multicolumn{2}{|l|}{ Expected support during } \\
\hline \multicolumn{2}{|l|}{ an illness period } \\
\hline Low expected support & I.4I (0.58-3.47) \\
\hline \multicolumn{2}{|c|}{ Physical activity in spare-time } \\
\hline Low activities & $1.44(0.79-2.62)$ \\
\hline \multicolumn{2}{|l|}{ Alcohol beverages } \\
\hline$\geq 4 /$ day & Ref \\
\hline $1-3 /$ day & $0.81(0.43-1.53)$ \\
\hline Seldom/never & $0.85(0.46-1.54)$ \\
\hline Smoking & $1.00(0.67-1.49)$ \\
\hline Weight & $0.99(0.98-1.01)$ \\
\hline
\end{tabular}

including size, density, reciprocity, durability, intensity, and frequency; 2) 'social relationships' which refers to the existence, quantity, and type of relationships; 3) and 'social support' which refers to the resources provided by others (emotional, functional, and informational) and the quality of those resources. ${ }^{3}$

In our study, we have used single-living as a proxy for low social support and showed that single-living patients were less likely than nonsingle-living patients to have daily contact with a social network and were less likely to expect support from others during an illness. However, single-living was the only social variable associated with death. Low frequency of contacts to the network of people surrounding the patients and the patients' perceptions about lack of support during an illness was not associated with mortality in our study. This
Table 4 Clinical predictors of long-term all-cause mortality among employed patients after acute myocardial infarction

\begin{tabular}{ll}
\hline Variable & Hazard ratio (95\% Cl) \\
\hline Prior MI & $1.80(1.13-2.85)$ \\
Diabetes & $2.90(1.55-5.43)$ \\
Hypertension & $1.69(1.12-2.55)$ \\
COPD & $2.00(0.93-4.32)$ \\
Medication & \\
$\quad$ Painkillers & $2.47(1.35-4.5 \mathrm{I})$ \\
$\quad$ Nervous disease & $0.94(0.23-3.80)$ \\
Ejection fraction & $0.97(0.95-0.99)$ \\
$\quad<35 \%$ & $2.27(1.36-3.80)$ \\
$\quad 35 \%-45 \%$ & $1.28(0.80-2.03)$ \\
$>45 \%$ & $R e f$ \\
Heart failure & $2.14(1.44-3.19)$ \\
Atrial fibrillation & $3.05(1.83-5.08)$ \\
Ventricular arrhythmias & $1.21(0.66-2.20)$ \\
Block & $0.83(0.31-2.26)$ \\
Reinfarction & $1.50(0.66-3.43)$ \\
Thrombolysis & $0.86(0.59-1.26)$ \\
Beta blocker & $0.80(0.53-1.21)$ \\
ACE-inhibitor & $2.09(1.38-3.17)$ \\
No exercise-test & $1.53(0.95-2.44)$ \\
\hline Ab &
\end{tabular}

Abbreviations: $\mathrm{ACE}$, angiotensin-converting enzyme; $\mathrm{Cl}$, confidence interval; $\mathrm{MI}$, myocardial infarction; COPD, chronic obstructive pulmonary disease.

may indicate that the effect of single-living on outcome after MI is not mediated through these factors.

Social support is thought to affect illness through its influence on behavioural patterns that could increase or decrease risk for disease or through effects on biological responses. ${ }^{1,3}$ However, the precise mechanisms or mediating role of low social support has not been defined. Whether the association is mediated through classical risk factors or independent of these is not clearly established. Hypothetically, single-living patients may have a worse risk-factor profile than patients living with a partner. Our study, however, does not support this conjecture.

Table 5 Final cox proportional hazard model

\begin{tabular}{ll}
\hline Variable & HR $(95 \% \mathbf{C I})$ \\
\hline Single-living & $2.55(\mathrm{I} .52-4.30)$ \\
Age & $\mathrm{I} .06(\mathrm{I} .03-1.09)$ \\
Diabetes & $2.56(1.35-4.85)$ \\
Atrial fibrillation & $2.63(1.52-4.55)$ \\
Ejection fraction & \\
$\quad>45 \%$ & Ref \\
$35-45 \%$ & $1.23(0.72-2.10)$ \\
$<35 \%$ & $1.75(1.04-2.95)$ \\
\hline
\end{tabular}

Abbreviations: $\mathrm{HR}$, hazard ratio; $\mathrm{Cl}$, confidence interval. 
Living alone has been associated with a greater risk of depression after MI. ${ }^{15}$ Since depression is associated with death after MI, it would be relevant to consider depression as a potential confounding factor in the association between single-living and death. ${ }^{15}$ We did not formally evaluate the patients for depression; however, treatment with medication against neurological disorders did not differ in relation to living arrangements in our study. Furthermore, there were no differences according to living arrangement in the proportion of patients reporting being seldom or never happy and satisfied with their lives. Based on these observations, the prevalence of depression did not differ in the two groups at baseline, but one cannot rule out the appearance of a difference during the follow-up, a possibility we could not examine.

Biologically, living alone may give rise to changes in neurohormonal systems as well as pro-inflammatory and hypercoagulable states. ${ }^{5}$ Neurohormonal and inflammatory factors have been associated with cardiovascular risk factors and, independently, with development of cardiovascular disease. ${ }^{5}$ However, the mechanisms whereby living arrangements may affect biologic response have not been identified.

Our findings have potentially important clinical implications. Although there are no interventions against living arrangements with documented effect on adverse outcome after MI, we emphasize the importance of assessing living arrangements as a part of risk stratification after MI. More research is needed to identify interventions that might oppose the negative effects of single-living on mortality after MI.

It is beyond the scope of the present work to discuss the influence of other factors on long-term mortality after MI. However, in agreement with others we found that age, diabetes mellitus, atrial fibrillation, and reduced left ventricular function were also independent predictors of death after MI. ${ }^{18-21}$

Our study has several limitations. We examined the effect of single-living in a sample of employed patients with MI. Results from this selected group may, therefore, only be applicable to a population of relatively young, actively employed patients. The total duration of living alone before and after the MI was not known in our study. The living arrangements of patient groups could have changed in both directions during the long follow-up period, causing misclassification of the living-arrangement status. We were unable to examine differences in health behaviors and health lifestyles during the follow-up period. Changes in health behavior after MI could also bias the observed association between singleliving and mortality. Finally, the small sample size limited the precision in our estimates, while low numbers of women preclude definite conclusions regarding the role of gender in the association under study.

\section{Conclusion}

The present study is the first to investigate the association between single-living and long-term all-cause mortality among employed patients with MI. We show that singleliving is an independent predictor of mortality up to 16 years after myocardial infarction.

\section{Disclosures}

This study was supported by grants from The Danish Heart Foundation and The Health Insurance Foundation, Copenhagen, Denmark. The authors report no conflicts of interest in this work.

\section{References}

1. Hemingway H, Marmot M. Psychosocial factors in the aetiology and prognosis of coronary heart disease: systematic review of prospective cohort studies. BMJ. 1999;318:1460-1467.

2. Nielsen KM, Faergeman O, Larsen ML, Foldspang A. Danish singles have a twofold risk of acute coronary syndrome: data from a cohort of 138.290 persons. J Epidemiol Community Health. 2006;60:721-728.

3. Mookadam F, Arthur HM. Social support and its relationship to morbidity and mortality after acute myocardial infarction. Systematic overview. Arch Intern Med. 2004;164:1514-1518.

4. Kaplan RM, Kronick RG. Marital status and longevity in the United States population. J Epidemiol Community Health. 2006;60: 760-765.

5. Schmaltz HN, Southern D, Ghali WA, et al. Living alone, patient sex and mortality after acute myocardial infarction. $J$ Gen Intern Med. 2007;22:572-578.

6. Case RB, Moss AJ, Case N, McDermott M, Eberly S. Living alone after myocardial infarction. Impact on prognosis. JAMA. 1992;267(4): 515-519.

7. Alter D, Chong A, Austin PC, et al. Socioeconomic status and mortality after acute myocardial infarction. Ann Intern Med. 2006;144: $82-93$.

8. O'Shea JC, Wilcox RG, Skene AM, et al. Comparison of outcomes of patient with myocardial infarction when living alone versus those not living alone. Am J Cardiology. 2002;90:1374-1377.

9. Bartley M. Unemployment and ill health: understanding the relationship. J Epidemiol Community Health. 1994;48:333-337.

10. Nielsen FE, Sørensen HT, Skagen K. A prospective study found impaired left ventricular function predicted job retirement after acute myocardial infarction. J Clin Epidemiol. 2004;57:837-842.

11. Berning J, Steensgaard-Hansen F. Early estimation of risk by echocardiographic determination of wall motion index in an unselected population with acute myocardial infarction. Am J Cardiol. 1990;65:567-576.

12. Berning J, Nielsen JR, Lauenbjerg J, Fogh J, Mickley H, Andersen PE. Rapid estimation of left ventricular ejection fraction in acute myocardial infarction by echocardiographic wall motion analysis. Cardiology. 1992;80:257-266.

13. Collett D. Modelling Survival Data in Medical Research. 2nd. ed. New York, NY: Chapman and Hall/CRC; 2003.

14. Case RB, Moss AJ, Case N, McDermott M, Eberly S. Living alone after myocardial infarction. Impact on prognosis. JAMA. 1992;267: $515-519$. 
15. Frasure-Smith N, Lespérance F, Gravel G, et al. Social support, depression, and mortality during the first year after myocardial infarction. Circulation. 2000;101(16):1919-1924.

16. Pedersen SS, van Domburg RT, Larsen ML. The effect of low social suppport on short-term prognosis in patients following a first myocardial infarction. Scand J Psychol. 2004;45(4):313-318.

17. Lett HS, Blumenthal JA, Babyak MA, et al. Social support and prognosis at increased psychosocial risk recovering from myocardial infarction. Health Psychol. 2007;26(4):418-427.

18. Marchioli R, Avanzini F, Barzi F, et al. Assessment of absolute risk of death after myocardial infarction by use of multiple-risk-factor assessment equations: GISSI-Prevenzione mortality risk chart. Eur Heart J. 2001;22(22):2085-2103.
19. Norhammar A, Lindbäck J, Rydén L, Wallentin L, Stenestrand U. Improved but still high short- and long-term mortality rates after myocardial infarction in patients with diabetes mellitus: a time-trend report from the Swedish Register of Information and Knowledge about Swedish Heart Intensive Care Admission. Heart. 2007;93(2): $1577-1583$

20. Schmitt J, Duray G, Gersh BJ, Hohnloser SH. Atrial fibrillation in acute myocardial infarction: a systematic review of the incidence, clinical features and prognostic implications. Eur Heart J. 2009;30(9): $1038-1045$.

21. Møller JE, Hillis GS, Oh JK, Reeder GS, Gersh BJ, Pellikka PA. Wall motion score index and ejection fraction for risk stratification after acute myocardial infarction. Am Heart J. 2006;151(2):419-425.
Clinical Epidemiology

\section{Publish your work in this journal}

Clinical Epidemiology is an international, peer-reviewed, open access journal focusing on disease and drug epidemiology, identification of risk factors and screening procedures to develop optimal preventative initiatives and programs. Specific topics include: diagnosis, prognosis, treatment, screening, prevention, risk factor modification, systematic

Submit your manuscript here: http://www.dovepress.com/clinical-epidemiology-journal

\section{Dovepress}

reviews, risk \& safety of medical interventions, epidemiology \& biostatical methods, evaluation of guidelines, translational medicine, health policies \& economic evaluations. The manuscript management system is completely online and includes a very quick and fair peer-review system, which is all easy to use. 